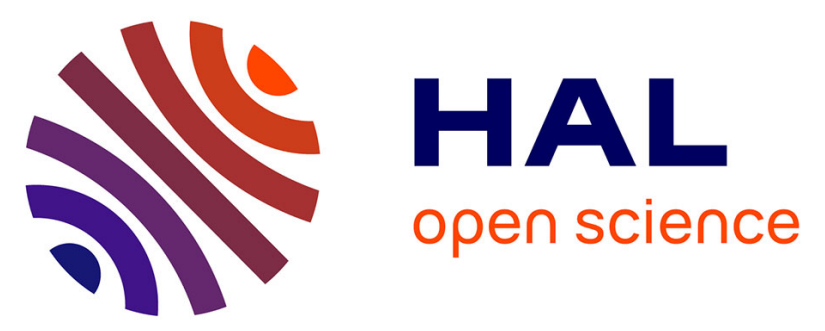

\title{
A new distribution-free adaptive sample size control chart for a finite production horizon and its application in monitoring fill volume of soft drink beverage bottles
}

Mahfuza Khatun, Michael B.C. Khoo, Sajal Saha, Philippe Castagliola

\section{- To cite this version:}

Mahfuza Khatun, Michael B.C. Khoo, Sajal Saha, Philippe Castagliola. A new distribution-free adaptive sample size control chart for a finite production horizon and its application in monitoring fill volume of soft drink beverage bottles. Applied Stochastic Models in Business and Industry, 2021, 37 (1), pp.84-97. 10.1002/asmb.2545 . hal-03321812

\author{
HAL Id: hal-03321812 \\ https://hal.science/hal-03321812
}

Submitted on 18 Aug 2021

HAL is a multi-disciplinary open access archive for the deposit and dissemination of scientific research documents, whether they are published or not. The documents may come from teaching and research institutions in France or abroad, or from public or private research centers.
L'archive ouverte pluridisciplinaire HAL, est destinée au dépôt et à la diffusion de documents scientifiques de niveau recherche, publiés ou non, émanant des établissements d'enseignement et de recherche français ou étrangers, des laboratoires publics ou privés. 
A New Distribution-free Adaptive Sample Size Control Chart for a Finite Production

Horizon and its Application in Monitoring Fill Volume of Soft Drink Beverage Bottles

\author{
Mahfuza Khatun \\ Department of Mathematics, \\ American International University-Bangladesh, \\ Kuratoli, kuril, Dhaka, Bangladesh \\ mahfuza@aiub.edu; mahfuzab@gmail.com
}

Michael B. C. Khoo (Corresponding Author)

School of Mathematical Sciences,

Universiti Sains Malaysia, 11800 Penang, Malaysia

mkbc@usm.my

ORCID: 0000-0002-3245-1127

\author{
Sajal Saha \\ Department of Mathematics, \\ International University of Business Agriculture and Technology, \\ Dhaka, Bangladesh \\ sajal.saha@iubat.edu \\ Philippe Castagliola \\ Université de Nantes \& LS2N UMR CNRS 6004 \\ Nantes, France \\ philippe.castagliola@univ-nantes.fr \\ ORCID: 0000-0002-9532-4029
}

\title{
Acknowledgements
}

This research is supported by the Universiti Sains Malaysia, Research University (RUI) grant, number 1001.PMATHS.8011039. 


\begin{abstract}
Nonparametric control charts have received increasing attention in process monitoring. In this paper, a new nonparametric sign (SN) control chart with variable sample size (VSS) for a finite horizon process is developed. The novelty of this research lies in the incorporation of the VSS technique into the nonparametric SN chart for a finite horizon process, hence, resulting in the development of a more sensitive nonparametric short run chart. The statistical performance of the new nonparametric VSS SN control chart is evaluated and compared with the existing fixed sample size (FSS) SN chart for a finite horizon process. The charts' performances are compared using the truncated average run length (TARL) and truncated standard deviation of the run length (TSDRL) criteria. The results obtained show that the nonparametric VSS SN short run chart is always quicker than the FSS SN short run chart in detecting process shifts for various underlying process distributions, hence, reducing scrap and rework cost. Finally, an application of the proposed control charting scheme is shown through a real-life example on the fill volume of soft drink beverage bottles.
\end{abstract}

Keywords: nonparametric, variable sample size, finite production horizon, Markov chain, truncated average run length

\title{
1 Introduction
}

In Statistical Process Control (SPC), control charts are extensively implemented to monitor and improve the quality of a process. In a typical design of control charts for continuous data, the process observations are assumed to follow a specified probability distribution. Control charts established under the normality assumption may provide more frequent false alarms when the quality characteristic of interest actually follows a non-normal or an unknown distribution. Therefore, nonparametric control charts have been introduced to address this 
problem. Over the last decade or so, nonparametric (or distribution-free) control charts that allow many assumptions about the process distribution to be relaxed, have become quite popular and have been widely investigated in the SPC literature. The following studies are some of the existing research works present in the literature. Parent ${ }^{1}$ and Reynolds ${ }^{2}$ developed control charts based on the signed sequential ranks of the observations. Meanwhile, Bakir ${ }^{3}$ and Bakir and Reynolds ${ }^{4}$ developed a cumulative sum (CUSUM) chart based on the Wilcoxon signed rank statistic. Park ${ }^{5}$ proposed Shewhart sign charts and Wilcoxon signed rank charts for asymmetrical distributions. Furthermore, Amin and Searcy ${ }^{6}$ studied the properties of the exponentially weighted moving average (EWMA) chart for the Wilcoxon signed rank statistic. Amin et al. ${ }^{7}$ designed a nonparametric control chart based on the sign statistic. Subsequently, Amin and Widmaier ${ }^{8}$ proposed a variable sampling interval sign control chart.

Chakraborti, Van der Lann, and Bakir ${ }^{9}$ presented a review on nonparametric control charts. Bakir ${ }^{10,11}$ proposed a distribution-free control chart using the signed ranks and sign rank-like statistics. Chakraborti and Eryilmaz ${ }^{12}$ proposed the nonparametric Shewhart type sign rank control chart based on runs rules while Chakraborti and Graham ${ }^{13}$ presented some nonparametric control charts. Das, and Bhattacharya ${ }^{14}$ proposed a nonparametric control chart to monitor the process variability, while $\mathrm{Li}$, Tang, and $\mathrm{Ng}{ }^{15}$ proposed two nonparametric counterparts of the CUSUM and EWMA control charts based on the Wilcoxon signed-sum test for detecting process mean shifts. Moreover, Human, Chakraborti, and Smit ${ }^{16}$ proposed nonparametric Shewhart-type sign control charts based on runs rules. Graham, Chakraborti, and Human ${ }^{17}$ investigated the nonparametric EWMA control chart for independent and identically distributed individual observations based on the sign statistic. Additionally, Yang, Lin, and Cheng ${ }^{18}$ developed a new control chart using the EWMA sign statistic. Aslam, Azam, and Jun ${ }^{19}$ proposed an EWMA sign chart using repetitive sampling. 
Meanwhile, $\mathrm{Lu}^{20}$ proposed an extended nonparametric EWMA sign control chart and Asghari et al. ${ }^{21}$ developed a sign control chart based on ranked set sampling. Chakraborti and Graham ${ }^{22}$ explained some of the latest developments on univariate and multivariate nonparametric charts.

For many manufacturers, manufacturing is now done in high-variation/low-volume environments. There are many situations where the production horizon is very short, i.e. a few hours or a few days, and it is considered as finite. The first control charting scheme designed for the finite production horizon was introduced by Ladany ${ }^{23}$ who presented the economic optimization design of a $p$ chart for short run. This pioneering work was extended by Ladany and Bedi, ${ }^{24}$ who introduced a similar model where the duration of the production run is a variable. Control charts specifically designed for processes with finite production horizon have been discussed in Del Castillo and Montgomery. ${ }^{25,}{ }^{26}$ Bayesian type control charts for monitoring the sample mean during a short run have been proposed by Calabrese, ${ }^{27}$ Tagaras, ${ }^{28}$ Tagaras and Nikolaidis, ${ }^{29}$ Nenes and Tagaras, ${ }^{30}$ and Kooli and Limam. ${ }^{31}$ Nenes and Tagaras ${ }^{32}$ investigated the performance of the CUSUM control chart under the assumption of a finite run. Additionally, Celano et al. ${ }^{33}$ investigated the statistical performances of the Shewhart and EWMA $t$ control charts for a finite horizon process. Subsequently, Celano et al. ${ }^{34}$ studied the statistical performances of the Shewhart, EWMA and CUSUM $t$ charts for short production runs when the shift size is unknown. $\mathrm{Li}$ and $\mathrm{Pu}^{35}$ developed performance measures for the two-sided Shewhart, CUSUM and EWMA charts for finite production horizon. Castagliola et al. ${ }^{36}$ investigated one-sided Shewhart-type charts for monitoring the $\mathrm{CV}$ in a finite horizon context.

According to Montgomery ${ }^{37}$, if there is no knowledge about the distribution of observations and its parameters, an easy approach is to monitor a statistic that deviates from a nominal (or target) value of the quality characteristic. This target value can refer to any 
parameter of the distribution of observations or any quantile of interest. In the literature, only Celano et al. ${ }^{38,39}$ presented a nonparametric (Shewhart sign) chart for a finite production horizon. In the context of incorporating adaptive procedure into a control chart for finite production horizon, Castagliola et al. ${ }^{40}$ developed the VSS version of the $t$ chart for short production run using the Markov chain approach. Nenes et al. ${ }^{41}$ introduced a control chart for short production runs with variable sampling interval. Amdouni et al. ${ }^{42}$ proposed an adaptive Shewhart chart with a VSS strategy to monitor the coefficient of variation in short production runs. In addition, Park and Choi ${ }^{43}$, and Park and Reynolds ${ }^{44,} 45$ investigated the economic designs of VSS type charts. On similar lines, the double sampling (DS) chart enables the sample size to be varied at each sampling stage. The DS $\bar{X}$ chart was introduced by Croasdale ${ }^{46}$ and improved upon by Daudin ${ }^{47}$. The DS chart utilizes information from either the first sample or the combined first and second samples in making a decision about the status of a process, hence, it allows the sample size to be varied. Subsequently, Irianto and Shinozaki ${ }^{48}$, Carot et al. ${ }^{49}$, and He and Grigoryan ${ }^{50}$ presented numerous designs and extensions of the univariate DS charts.

The in-control performance of the SN short run chart is distribution-free. Typically, only the target value is known and the set-up activities are conducted to position the process exactly on the target. Information about the target value for the median is sufficient to implement the SN short run chart, without any reference to the distributional shape of the process. In processes with short production runs, a moderately small sample size, $n$ can be adopted to implement the SN chart with a sufficiently low false alarm rate by the end of the run.

Over the last decade or so, nonparametric charts have gained increasing attention in process monitoring. Although various types of adaptive parametric charts exist in the literature, the same is not true for nonparametric charts in short runs. Adaptive charts are 
implemented by varying the charts' parameters (such as sample size, sampling interval and limits' constants) based on the quality level of the process given by the prior sample. Findings have shown that adaptive charts are substantially more efficient than traditional charts with fixed parameters.

The aim of this paper is to propose a nonparametric sign $(\mathrm{SN})$ chart with variable sample size (VSS), for process monitoring in finite production horizon. The VSS technique is incorporated into the $\mathrm{SN}$ chart for finite production horizon to develop an efficient nonparametric chart in short runs for a quicker detection of process shifts. The contribution of this paper lies in the development of a new nonparametric control chart for monitoring a manufacturing process with a non-normal or an unknown distribution, coupled with a manufacturing environment producing high-variation/low-volume products.

The remainder of this paper is structured as follows: In Section 2, the proposed VSS SN short run chart is discussed. In Section 3, the statistical measures of performance are outlined. Meanwhile, Section 4 presents the methodology and a discussion of the results. An illustrative example is given in Section 5 to show the implementation of the VSS SN short run chart. Finally, conclusions and suggestions for future research are discussed in Section 6.

\section{The VSS SN Control Chart for a Finite Production Horizon}

Assume that a manufacturing process produces a small number $N$ of parts in a production horizon of limited length, which is equal to $H$ hours. The location of a quality characteristic of interest, $X$ around a specified target value is monitored during the production run. Note that $X$ is assumed to be a continuous random variable with an unknown distribution. We select the median, $\theta$ of the distribution of the random variable, as the location parameter to be

monitored with the VSS SN short run chart. Let $T_{M}$ and $\theta_{0}$ denote the target and in-control values of the median, respectively. At the beginning of a process setup, adjustments are made 
before the production run starts with the objective of putting the in-control process median $\theta_{0}$ on the target $T_{M}$. In a perfect initial setup, $\theta_{0}=T_{M}$, otherwise, the process starts shifted away from the target value and the control chart should trigger a signal as soon as possible. It is assumed that the in-control operating condition for a process with finite production horizon starts without any setup error and runs without the occurrence of any assignable cause.

Let $I$ be the number of scheduled inspections within the production horizon $H$. The interval between two successive inspections is $h=\frac{H}{I+1}$ hours. It is assumed that no inspection takes place at the end of the run. If the run ends without any signal in the $I$ inspections, then the total number of inspections is assigned with the value $I+1$. At each inspection, $i=1,2, \ldots, I$, the sample size $n(i)$ is adopted. Hence, when a fixed parameter short run chart is used to monitor a process, the fixed sample size $n(i)=n_{0}$ is adopted. In contrast, if a VSS SN short run chart is implemented, the sample size $n(i)$ is varied at two levels, $n_{S}$ (small sample size) and $n_{L}$ (large sample size), with $n_{S}<n_{L}$. It is worth noting that $n_{0} \leq N /(I+1)$ and $n_{L} \leq N /(I+1)$ for the fixed parameter and VSS SN short run charts, respectively. We also assume that there is independence among the inspected parts within a sample and among samples. Let $\left\{X_{i, 1}, X_{i, 2}, \ldots, X_{i, n(i)}\right\}$ be a sample of size $n(i)$, at inspection $i$ $=1,2, \ldots, I$. Each observation $X_{i, j}$ follows an unknown continuous process distribution with cumulative distribution function (cdf), $F_{X}(\cdot)$. The following statistic is considered for the VSS SN short run chart:

$$
S N_{i}=\sum_{j=1}^{n(i)} \operatorname{sign}\left(X_{i, j}-T_{M}\right)
$$

where 


$$
\operatorname{sign}(x)=\left\{\begin{array}{cc}
1 & \text { if } x>0 \\
0 & \text { if } x=0 \\
-1 & \text { if } x<0
\end{array}\right.
$$

Note that the condition $\operatorname{sign}(x)=0$ will supposedly not happen when the process distribution of the inspected parts is continuous. Additionally, it should be pointed out that following the definitions in Equations (1) and (2), the values assumed by $S N_{i}$ are $S N_{i} \in$ $\{-n(i),-n(i)+2, \ldots, n(i)-2, n(i)\}$. When the process starts in-control, the distribution of $S N_{i}$ can be easily obtained by considering the relationship $S N_{i}=2 D_{i}-n(i)$ (Amin, Reynolds, and Saad ${ }^{7}$ ), which is valid for continuous observations (inspected parts), $X_{i, j}$, where $D_{i}$ is the number of observations that exceed the in-control median, $T_{M}$, in a sample of size $n(i)$, i.e. the count of positive signs within a sample. When the process is in-control, $D_{i}$ is a binomial random variable with parameters $n(i)$ and $p_{0}$, i.e. $D_{i} \sim \operatorname{Bin}\left(n(i), p_{0}\right)$. Note that $p_{0}$ is the in-control probability for an observation to be larger than $\theta_{0}\left(=T_{M}\right)$, i.e. $p_{0}=P\left(X_{i, j}>T_{M} \mid \theta_{0}=T_{M}\right)=0.5$, for $i=1,2, \ldots, I$ and $j=1,2, \ldots, n(i)$. When the process has shifted away from the target value of the median, $T_{M}$ due to the occurrence of a setup error and/or an assignable cause, the out-of-control process median is $\theta_{1}=T_{M}+\delta \sigma_{0}$, where $\sigma_{0}$ is the in-control process standard deviation. Let $p_{\delta}=P\left(X_{i, j}>T_{M} \mid \theta_{1}=T_{M}+\delta \sigma_{0}\right)=1-F_{X}\left(T_{M} \mid \theta_{1}=T_{M}+\delta \sigma_{0}\right) \quad$ as $\quad$ the out-of-control probability of having an observation larger than $T_{M}$. The value of $p_{\delta}$ depends on the distribution of the observations and the shift size $\delta$.

The VSS SN short run chart has two warning limits, i.e.

$$
\begin{aligned}
& \mathrm{UWL}=k, \\
& \mathrm{LWL}=-k,
\end{aligned}
$$


and two control limits, i.e.

$$
\begin{aligned}
\mathrm{UCL} & =c, \\
\mathrm{LCL} & =-c,
\end{aligned}
$$

under the assumption that $c<n_{S}$ (so that it is possible for $S N_{i}$ to be less than $-c$ or greater than $c$, irrespective of whether $n_{S}$ or $n_{L}$ is adopted, in order for the chart to signal an out-ofcontrol when the process shifts) and $k<c$. The VSS SN short run chart is implemented as follows:

- If the discrete value $S N_{i}$ falls in the interval $I_{S} \in\{-k,-k+1, \ldots, k-1, k\}$ (the control region), the process is declared as in-control and the sample size adopted for the next inspection is $n(i+1)=n_{S}$.

- If the discrete value $S N_{i}$ falls in the interval $I_{L} \in\{-c,-c+1, \ldots,-k-1\} \cup\{k+1, k+$ $2, \ldots, c\}$ (the warning region), the process is also declared as in-control but the sample size adopted for the next inspection is $n(i+1)=n_{L}$.

- If $S N_{i}<-c$ or $S N_{i}>c$, the process is declared as out-of-control and a search for the assignable cause(s) that lead to the out-of-control signal must be conducted. After the detection and removal of the assignable cause(s), process monitoring is resumed with a sample size of $n(i+1)=n_{S}$.

For the FSS SN short run chart, $n(i)=n_{0}$ is always considered, for $i=1,2, \ldots, I$. Then the FSS SN short run chart's control limits are defined as follows (Celano et al. ${ }^{38}$ ):

$$
\begin{aligned}
\mathrm{UCL}_{f} & =c_{f}, \\
\mathrm{LCL}_{f} & =-c_{f},
\end{aligned}
$$

where $c_{f}<n_{0}$. The FSS SN short run chart signals an out-of-control when the $S N_{i}$ statistic in Equation (1) exceeds the limits in Equations (5a) and (5b). 


\section{Statistical Measures of Performance}

The Markov chain approach can be used to derive the performance measures of the VSS SN short run chart. Three Markov chain states are defined. States 1, 2 and 3 represent the cases $S N_{i} \in I_{S}, S N_{i} \in I_{L}$ and $S N_{i}<-c \cup S N_{i}>c$. Consequently, a $3 \times 3$ transition probability matrix, $\mathbf{P}$, representing the probabilities of shifting from one state to another is given as

$$
\mathbf{P}=\left(\begin{array}{cc}
\mathbf{Q} & \mathbf{r} \\
\mathbf{0}^{\mathrm{T}} & 1
\end{array}\right)=\left(\begin{array}{cc|c}
p_{S}\left(n_{S}\right) & p_{L}\left(n_{S}\right) & 1-p_{S}\left(n_{S}\right)-p_{L}\left(n_{S}\right) \\
p_{S}\left(n_{L}\right) & p_{L}\left(n_{L}\right) & 1-p_{S}\left(n_{L}\right)-p_{L}\left(n_{L}\right) \\
\hline 0 & 0 & 1
\end{array}\right)
$$

Here, $p_{S}(n(i))=P\left(S N_{i} \in I_{S} \mid n(i)\right)$ and $p_{L}(n(i))=P\left(S N_{i} \in I_{L} \mid n(i)\right)$ with $n(i) \in\left\{n_{S}, n_{L}\right\}$.

Note that $\mathbf{Q}$ is a $(2 \times 2)$ transition probability matrix of transient probabilities and the vector $\mathbf{r}$ satisfies $\mathbf{r}=\mathbf{1}-\mathbf{Q 1}$ (i.e. row probabilities must have a sum of one), with $\mathbf{1}=(1,1)^{\mathrm{T}}$.

By definition, we have

$$
\begin{aligned}
p_{S}(n(i)) & =P\left(-k \leq S N_{i} \leq k \mid n(i), p_{\delta}\right) \\
& =P\left(\frac{n(i)-k}{2} \leq D_{i} \leq \frac{n(i)+k}{2} \mid n(i), p_{\delta}\right) \\
& =F_{B}\left(\frac{n(i)+k}{2} \mid n(i), p_{\delta}\right)-F_{B}\left(\frac{n(i)-k}{2}-1 \mid n(i), p_{\delta}\right), \\
p_{L}(n(i)) & =P\left(k<S N_{i} \leq c \mid n(i), p_{\delta}\right)+P\left(-c \leq S N_{i}<-k \mid n(i), p_{\delta}\right) \\
& =P\left(\frac{n(i)+k}{2}<D_{i} \leq \frac{n(i)+c}{2} \mid n(i), p_{\delta}\right) \\
& +P\left(\frac{n(i)-c}{2} \leq D_{i}<\frac{n(i)-k}{2} \mid n(i), p_{\delta}\right)
\end{aligned}
$$




$$
\begin{aligned}
=F_{B}\left(\frac{n(i)+c}{2} \mid n(i), p_{\delta}\right)-F_{B}\left(\frac{n(i)+k}{2} \mid n(i), p_{\delta}\right) \\
+F_{B}\left(\frac{n(i)-k}{2}-1 \mid n(i), p_{\delta}\right)-F_{B}\left(\frac{n(i)-c}{2}-1 \mid n(i), p_{\delta}\right),
\end{aligned}
$$

where $F_{B}\left(\cdot \mid n(i), p_{\delta}\right)$ is the cdf of a binomial distribution with parameters $n(i)$ and $p_{\delta}$. When the process is in-control, $p_{\delta}=p_{0}=0.5$ in Equations (7) and (8).

The production run ends after the fixed rolling horizon $H$, which coincides with the production lot cycle time. Thus, the statistical measures of performance of the chart are functions of the finite number $I$ of scheduled inspections. The performance measures of control charts for a finite production horizon were developed by Nenes and Tagaras. ${ }^{32}$ Consequently, the classical average run length (ARL) formula for an infinite production horizon is replaced by the TARL formula for a finite production horizon. Here, TARL represents the average number of inspections (or samples) required until an out-of-control signal is triggered or until the completion of the process, whichever occurs first. Let $\mathrm{TARL}_{0}$ and $\mathrm{TARL}_{1}$ denote the in-control and out-of-control TARLs, respectively. Note that if the run ends without any signal in the $I$ inspections, then the truncated run length (TRL) value is equal to $I+1$. The TARL value can be computed as follows:

$$
\mathrm{TARL}=\mathbf{q}^{\mathrm{T}}\left(\sum_{m=0}^{I} \mathbf{Q}^{m}\right) \mathbf{1} .
$$

Under the assumption of a perfect initial setup, the process always starts under the on-target condition. For this reason, we choose the initial probability vector, $\mathbf{q}=(1,0)^{\mathrm{T}}$, i.e. the initial sample size is set as $n_{s}$. Otherwise, an initial setup can be accounted for by selecting $\mathbf{q}=(0,1)^{\mathrm{T}}$, i.e. the initial sample size is set as $n_{L}$. 
Since $\mathbf{Q}$ is the transition probability matrix for the transient states, then (Castagliola et al. ${ }^{40}$ )

$$
\sum_{m=0}^{I} \mathbf{Q}^{m}=(\mathbf{I}-\mathbf{Q})^{-1}\left(\mathbf{I}-\mathbf{Q}^{I+1}\right)
$$

where $\mathbf{I}$ is the $2 \times 2$ identity matrix. The second non-central moment of TRL, i.e. $\mathrm{TRL} 2=\mathrm{E}\left(\mathrm{TRL}^{2}\right)$ is obtained as

$$
\operatorname{TRL} 2=\mathbf{q}^{\mathrm{T}}\left(\sum_{m=0}^{I}(2 m+1) \mathbf{Q}^{m}\right) \mathbf{1} .
$$

It follows that TSDRL is

$$
\mathrm{TSDRL}=\sqrt{\mathrm{TRL} 2-\mathrm{TARL}^{2}}
$$

In order to ensure a fair comparison between the VSS SN and FSS SN short run charts, we have to make sure that the in-control average sample size $\left(\mathrm{ASS}_{0}\right)$ of the VSS SN short run chart is equal to the fixed sample size, $n_{0}$ selected for the FSS SN short run chart. The ASS is the ratio between the expected total number of observations taken during a short production run and the number $I$ of scheduled inspections, i.e.

$$
\mathrm{ASS}=\frac{1}{I} \mathrm{E}\left(\sum_{i=1}^{I} n(i)\right)=\frac{1}{I} \sum_{i=1}^{I} \mathrm{E}(n(i)) .
$$

For estimating the ASS, Castagliola et al. ${ }^{40}$ suggested modifying $\mathbf{P}$ in Equation (6) by assuming that after an out-of-control point falls beyond the control limits, the quality practitioner completes the actions designed for searching and if necessary, eliminating the assignable cause before the next inspection $i+1$ with $n(i+1)=n_{S}$. Therefore, all states are now considered as accessible and the modified transition probability matrix, $\widetilde{\mathbf{P}}$ is defined as follows: 


$$
\widetilde{\mathbf{P}}=\left(\begin{array}{lll}
p_{S}\left(n_{S}\right) & p_{L}\left(n_{S}\right) & 1-p_{S}\left(n_{S}\right)-p_{L}\left(n_{S}\right) \\
p_{S}\left(n_{L}\right) & p_{L}\left(n_{L}\right) & 1-p_{S}\left(n_{L}\right)-p_{L}\left(n_{L}\right) \\
p_{S}\left(n_{S}\right) & p_{L}\left(n_{S}\right) & 1-p_{S}\left(n_{S}\right)-p_{L}\left(n_{S}\right)
\end{array}\right)
$$

Using the matrix $\widetilde{\mathbf{P}}, \mathrm{E}(n(i))$ is computed as follows:

$$
\mathrm{E}(n(i))=\widetilde{\mathbf{q}}^{\mathrm{T}} \widetilde{\mathbf{P}}^{i-1}\left(n_{S}, n_{L}, n_{S}\right)^{\mathrm{T}},
$$

where $\widetilde{\mathbf{q}}^{\mathrm{T}}=(1,0,0)$ is the vector of initial probabilities of the modified Markov chain. Consequently, by substituting Equation (15) into Equation (13), the average sample size is

$$
\operatorname{ASS}=\frac{1}{I} \widetilde{\mathbf{q}}^{\mathrm{T}}\left(\sum_{i=1}^{I} \widetilde{\mathbf{P}}^{i-1}\right)\left(n_{S}, n_{L}, n_{S}\right)^{\mathrm{T}}
$$

The in-control ASS $\left(\mathrm{ASS}_{0}\right)$ is computed using Equation (16) by letting $p_{\delta}=p_{0}=0.5$ in Equations (7) and (8).

\section{Numerical Analysis}

\subsection{Methodology}

In this section, we evaluate the robustness of the VSS SN short run chart with observations from non-normal distributions and the performance of the VSS SN short run chart for different process conditions with finite number of inspections. A performance comparison between the FSS SN and VSS SN short run charts is conducted to demonstrate the advantages of incorporating the VSS approach into the distribution-free SN short run chart. Similar to Celano et al., ${ }^{33}$ Castagliola et al. ${ }^{40}$ and Nenes et al., ${ }^{41}$ the sensitivity of the FSS SN and VSS SN short run charts to a shift of size $\delta$ in the process mean due to a setup error or an assignable cause occurring before the first scheduled inspection is evaluated. Consequently, the performances of the FSS SN and VSS SN short run charts are computed by considering an assignable cause occurring immediately after the start-up of the short run. Given the small number of possible inspection epochs in short production run, no steady state 
condition is achieved, hence, the zero-state $\mathrm{TARL}_{1}$ and $\mathrm{TSDRL}_{1}$ performance measures are computed only.

The out-of-control performances of these two charts are compared for the same nominal values of $\mathrm{TARL}_{0}=I \in\{10,30,50\}$ and $\mathrm{ASS}_{0}=n_{0} \in\{11,15,20\}$ to ensure a fair comparison. In the manufacturing context, it is a common practice to use moderately small sample sizes. Consequently, we restrict the choice of the sample sizes for $n_{S}$ and $n_{L}$ to $5 \leq n_{S}<n_{0}<n_{L} \leq 31$. The VSS SN short run chart's parameters $n_{S}, n_{L}, c$ and $k$ are chosen to satisfy the selected values of $I$ (or $\left.\mathrm{TARL}_{0}\right)$ and $n_{0}\left(\right.$ or $\mathrm{ASS}_{0}$ ). Sometimes, the $\mathrm{TARL}_{0}$ and $\mathrm{ASS}_{0}$ values may be larger than their anticipated value $\mathrm{TARL}_{0}=I$ and $\mathrm{ASS}_{0}=n_{0}$, respectively. However, $\mathrm{TARL}_{0}$ cannot exceed its bounding value, $\mathrm{TARL}_{0, \max }=I+1$ and $\mathrm{ASS}_{0}$ cannot exceed its bounding value, $\mathrm{ASS}_{0, \max }=n_{0}+1$. A VSS type chart is considered better than its competing chart if the $\mathrm{TARL}_{1}$ value of the former is lower than that of the latter, for a specified $\delta$, when the values of $\mathrm{TARL}_{0}$ and $\mathrm{ASS}_{0}$ are the same for all the charts under comparison.

The following underlying distributions considered by Celano et al. ${ }^{38}$ are also considered here to investigate the out-of-control performance of the VSS SN short run chart:

- Symmetric distributions - Standard normal $N(0,1)$, Student's $t(4)$ and $t(8)$, and laplace $(0,1 / \sqrt{2})$. The Student's $t$ and laplace (or double exponential) distributions are heavy-tailed and symmetric.

- Asymmetric distributions - $\operatorname{gamma}(a, b)$, with $(a, b)=(0.5,1)$ and $(1,1)$. These gamma distributions have different levels of symmetry and kurtosis, where $a$ and $b$ represent shape and scale parameters, respectively. 


\subsection{Results and Discussions}

Table 1 shows the computed parameter combinations $\left(n_{S}, n_{L}, c, k\right)$, for the $\left(I, n_{0}\right)$ pairs specified in Section 4.1, satisfying all the constraints mentioned in the said section. Note that if several parameter combinations $\left(n_{S}, n_{L}, c, k\right)$ satisfying the aforementioned constraints exist, for a particular $\left(I, n_{0}\right)$ pair, the parameter combination with a $\mathrm{TARL}_{0}$ value closest to $I$ is shown in Table 1 . The corresponding in-control TSDRL $\left(\mathrm{TSDRL}_{0}\right)$ and $\mathrm{ASS}_{0}$ values for each $\left(I, n_{0}\right)$ pair are also shown in Table 1 . The Markov chain approach enumerated in Section 3 is used to compute the parameter combinations $\left(n_{S}, n_{L}, c, k\right)$ using Matlab programs. Chakraborti, Van der Laan, and Bakir ${ }^{9}$ noted that a distribution-free chart will have the same run length distribution for every continuous distribution when the process is in-control (Chakraborti, Van der Laan, and Bakir ${ }^{9}$ ). In Table 1, suppose that a quality practitioner wants to design a VSS SN short run chart with $I=30$ and $n_{0}=15$, the chart's parameters that should be adopted are $n_{S}=13, n_{L}=21, c=11$ and $k=4$. These parameters produce $\mathrm{TARL}_{0}=30.01, \mathrm{TSDRL}_{0}=4.37$ and $\mathrm{ASS}_{0}=15.30$. Note that no parameter combination $\left(n_{S}, n_{L}, c, k\right)$, for $I=50$ and $n_{0}=11$, satisfying the constraints stipulated in Section 4.1 is available. For $I=50$, if $n_{0}$ is increased, the parameter combination $\left(n_{S}, n_{L}, c\right.$, $k$ ) that satisfies the aforementioned constraints exists, as in the case of $n_{0}=15$ and 20 (see Table 1).

\section{Insert Table 1 here}

Tables 2, 3 and 4 show the $\mathrm{TARL}_{1}$ and $\mathrm{TSDRL}_{1}$ values of the VSS SN short run chart, based on $\left(I, n_{0}\right)=(10,11),(30,15)$ and $(50,20)$, respectively, and $\delta \in\{0.2,0.4,0.6$, $0.8,1,1.25,1.5,1.75,2,2.5,3\}$, for the various distributions explained in Section 4.1. The VSS SN short run chart's parameters $n_{S}, n_{L}, c$ and $k$, for these $\left(I, n_{0}\right)$ pairs are obtained 
from Table 1. The simulation approach using Statistical Analysis System (SAS), based on 50,000 trials, is adopted to compute the $\mathrm{TARL}_{1}$ and $\mathrm{TSDRL}_{1}$ values of the VSS SN short run chart, for the $N(0,1), t(4), t(8), \operatorname{gamma}(0.5,1), \operatorname{gamma}(1,1)$ and laplace $(0,1 / \sqrt{2})$ distributions. Note that simulation is employed in order to generate random observations from the different types of distributions considered here, for the purpose of computing the $\mathrm{TARL}_{1}$ and $\mathrm{TSDRL}_{1}$ values based on these distributions. The simulation approach in computing $\mathrm{TARL}_{1}$ and $\mathrm{TSDRL}_{1}$ values is briefly discussed as follows: Firstly, random observations for the desired distribution are generated. Then using the parameter combination $\left(n_{S}, n_{L}, c, k\right)$ for a desired $\left(I, n_{0}\right)$ pair in Table 1 , the TRL value for each simulation trial is computed. The process of computing the TRL value is repeated for 50,000 simulation trials. Finally, the $\mathrm{TARL}_{1}$ and $\mathrm{TSDRL}_{1}$ values are obtained by taking the average and standard deviation of the 50,000 TRL values.

The first and second rows of each shift size, $\delta$ show the TARL $\mathrm{T}_{1}$ and TSDRL $\mathrm{TSalues}_{1}$ respectively, for a particular distribution and type of scheme (FSS or VSS). A simulation study has also been conducted for the remaining $\left(I, n_{0}\right)$ pairs in Table 1 , where similar results to that for $\left(I, n_{0}\right) \in\{(10,11),(30,15),(50,20)\}$ are obtained, hence, it suffices to only report the results for these three $\left(I, n_{0}\right)$ pairs in Tables $2-4$.

\section{Insert Tables $2-4$ here}

By examining Tables $2-4$, it is found that the VSS SN short run chart is always superior to the FSS SN short run chart, in terms of the $\mathrm{TARL}_{1}$ criterion, for all underlying distributions considered. For example, in Table 2 when $\delta=0.4, \mathrm{TARL}_{1} \in\{9.60,9.18,9.45$, $2.31,2.93,8.98\}$ for the FSS SN short run chart while the corresponding values for the VSS SN short run chart are $\mathrm{TARL}_{1} \in\{7.13,5.65,5.82,1.54,1.68,5.12\}$, hence, the percentages 
of improvement are $\{25.7 \%, 38.5 \%, 38.4 \%, 33.3 \%, 42.7 \%, 43.0 \%\}$, for the $N(0,1), t(4), t(8)$, $\operatorname{gamma}(0.5,1), \operatorname{gamma}(1,1)$ and laplace $(0,1 / \sqrt{2})$ distributions, respectively. From the $\mathrm{TARL}_{1}$ values in this example, it is clearly seen that the VSS SN short run chart has a lower $\mathrm{TARL}_{1}$ value than the FSS SN short run chart, for the same $\delta$ value and underlying distribution.

Higher $\mathrm{TARL}_{1}$ values are generally obtained for symmetric distributions. As an example, for symmetric distributions involving the VSS SN short run chart in Table 2 when $\delta$ $=0.6, \mathrm{TARL}_{1}=4.72,3.28,3.48$ and 3.10 for the $N(0,1), t(4), t(8)$ and laplace distributions, respectively. On the contrary, for asymmetric distributions involving the same chart and shift size, $\delta, \mathrm{TARL}_{1}=1.13$ and 1.20 , for the $\operatorname{gamma}(0.5,1)$ and $\operatorname{gamma}(1,1)$ distributions, respectively. In Table 2 , for all the distributions, $\mathrm{TARL}_{1} \leq 2$ for $\delta \geq 1.25$, for the VSS SN short run chart. Additionally, it is found that the $\mathrm{TARL}_{1}$ value decreases slightly with a decrease in the value of the shape parameter $a$, for the gamma distribution. For example, for the VSS SN short run chart in Table 3, when $\delta=0.4$, TARL ${ }_{1}=1.75$ and 1.65 , for $a=1$ and 0.5 , respectively.

On the other hand, the TRL distribution of the VSS SN short run chart is more dispersed (larger TSDRL $_{1}$ value) than that of the FSS SN short run chart, for small shifts (except for gamma $(0.5,1)$ and gamma $(1,1)$ distributions). However, for moderate and large shifts, the $\mathrm{TSDRL}_{1}$ values of the VSS SN short run chart are smaller than the corresponding ones of the FSS SN short run chart, for all underlying distributions. For example, in Table 2 when $\delta \in\{0.2,0.4,0.6,0.8,1,1.25,1.5,1.75,2,2.5,3\}$ and the underlying distribution is $N$ $(0,1), \mathrm{TSDRL}_{1} \in\{0.81,1.54,2.51,3.32,3.35,2.48,1.55,0.97,0.61,0.28,0.12\}$ for the FSS SN short run chart while for the VSS SN short run chart, TSDRL T $_{1} \in\{2.25,3.09,2.77,1.74$, 
$1.00,0.68,0.56,0.47,0.39,0.23,0.11\}$. In this example, it can be seen that the TSDRL values of the VSS SN short run chart are larger than that of the FSS SN short run chart, for $\delta$ $=0.2,0.4$ and 0.6 , while for larger $\delta$ values, the opposite is true.

The TRL distribution is generally less dispersed when the underlying distribution is gamma or laplace than the $N(0,1)$ distribution, as the gamma and laplace distributions result in smaller values of $\mathrm{TSDRL}_{1}$. For example, in Table 3 when $\delta=0.4, \mathrm{TSDRL}_{1}=4.33(9.54)$ for the VSS SN short run chart with the laplace $(N(0,1))$ distributions. The $N(0,1)$ distribution results in a smaller $\mathrm{TSDRL}_{1}$ value only when $\delta=0.2$. Note that for $0.20 \leq \delta \leq$ 0.80, the $\mathrm{TSDRL}_{1}$ values for the FSS SN short run chart increases with $\delta$, for the $N(0,1)$, $t(4), t(8)$ and laplace distributions. However, for $\delta \geq 1$, the $\mathrm{TSDRL}_{1}$ value decreases when $\delta$ increases, for both FSS and VSS SN short run charts.

The proposed VSS SN short run chart can be adopted in short production runs when the normality assumption of the underlying process cannot be satisfied or the underlying process distribution is unknown and when there is flexibility in varying the sample size. In comparison to the FSS SN short run chart, the VSS SN short run chart generally shows superior $\mathrm{TARL}_{1}$ and $\mathrm{TSDRL}_{1}$ performances. Hence, the VSS SN short run chart provides practitioners with a process monitoring tool which is efficient and can be used in any production process without any specific knowledge about the distribution of the continuous quality characteristic.

\section{An Illustrative Example}

A dataset from Montgomery ${ }^{37}$ is adopted to illustrate the implementation of the VSS SN short run chart. In this example, the fill volume of soft drink beverage bottles is the quality characteristic of interest. The volume is measured by placing a gage over the crown and 
comparing the height of the liquid in the neck of the bottle against a coded scale. On this scale, a reading of zero corresponds to the correct fill height, hence, $T_{M}=0$.

To ensure a fair comparison between the FSS and VSS SN short run charts, both charts are designed to have $I=10$. For the FSS SN short run chart, $n_{0}$ is set as 11 , while for the VSS SN short run chart, $n_{S}=9$ and $n_{L}=13$ are considered. Consequently, the UCL/LCL and UWL/LWL of the VSS SN short run chart are $\pm c= \pm 7$ and $\pm k= \pm 2$, respectively (see Table 1), while the $\mathrm{UCL}_{f} / \mathrm{LCL}_{f}$ of the FSS SN short run chart are $\pm c_{f}= \pm 9$. The values of the $S N_{i}$ statistic of the FSS and VSS SN short run charts are computed using Equation (1). For the VSS SN short run chart, the initial sample size is set as $n_{S}$.

In the implementation of the VSS SN short run chart, if the discrete value $S N_{i} \in I_{S} \in$ $\{-k,-k+1, \ldots, k-1, k\}=\{-2,-1,0,1,2\}$, the next sample of size $n_{S}(=9)$ should be taken, while if the discrete value $S N_{i} \in I_{L} \in\{-c,-c+1, \ldots,-k-1\} \cup\{k+1, k+2, \ldots, c\}$ $=\{-7,-6, \ldots,-3\} \cup\{3,4, \ldots, 7\}$, the next sample of size $n_{L}(=13)$ is taken. However, if $S N_{i}<-c(=-7)$ or $S N_{i}>c(=7)$, an out-of-control signal will be issued, where an investigation of the underlying process is made so that assignable causes are identified and removed in order to bring the process back into an in-control state. Then process monitoring is resumed by adopting a small sample size $\left(n_{S}\right)$ in taking the next sample. Contrastingly, for the FSS SN short run chart, an out-of-control signal is issued when $S N_{i}<-c_{f}(=-9)$ or $S N_{i}>c_{f}(=9)$.

For the purpose of illustration for the VSS SN short run chart, see the following discussion. Initially, the first sample $\left(n_{S}=9\right)$ is taken. Then $S N_{1}=5$ is computed (see Table 5). As $S N_{1} \in I_{L}$, the process is declared as in-control and the second sample $\left(n_{L}=13\right)$ is 
taken. As $S N_{2}=5 \in I_{L}$, the process is still in-control, where the third sample $\left(n_{L}=13\right)$ is taken. Consequently, $S N_{3}=-7$ is obtained. As $S N_{3} \in I_{L}$, the process is concluded as incontrol and the fourth sample $\left(n_{L}=13\right)$ is taken. AS $S N_{4}=1 \in I_{S}$, the process is still incontrol. Subsequently, the fifth sample of size $n_{S}=9$ is taken. The same process of taking the next sample, based on the current sample information, followed by computing the $S N_{i}$ statistic continues until the eighth sample. At the eighth sample $S N_{8}=-3$ is obtained.

\section{Insert Table 5 here}

As $S N_{8} \in I_{L}$, the process is concluded as in-control and the ninth sample $\left(n_{L}=13\right)$ is taken. Then $S N_{9}=-9$ is computed. Clearly, the process is declared as out-of-control by the VSS SN short run chart at the ninth sample as $S N_{9}<-c(=-7)$. Suppose that corrective actions are taken to rectify the out-of-control process, then the following sample (tenth sample) is taken with a small sample size of $n_{S}=9$ (see Table 5). Figure 1 shows the VSS SN short run chart plotted using the fill volume data of soft drink beverage bottles in Table 5 . Insert Figure 1 here

For comparison, the FSS SN short run chart is plotted in Figure 2. This chart is plotted using the $S N_{i}$ statistics in Table 5. Figure 2 shows that the FSS SN short run chart does not issue any out-of-control signal as $S N_{i} \in\left[-c_{f}, c_{f}\right]=[-9,9]$. This example shows that the VSS SN short run chart is more sensitive than the FSS SN short run chart in detecting an outof-control process.

Insert Figure 2 here

\section{Conclusion}


The paper proposes the VSS SN short run chart for use in a finite production horizon when the underlying distribution of the quality characteristic being monitored is nonnormal or unknown. The Markov chain approach is employed to derive the performance measures and compute the parameters of the proposed VSS SN short run chart. The proposed VSS SN chart is compared with the fixed sample size (FSS) SN chart in a short production runs environment. Simulation studies indicate that the nonparametric VSS SN short run chart outperforms the FSS SN short run chart in detecting all sizes of shifts in the process mean and the outperformance increases as the value of $n_{0}$ increases, for several symmetric and asymmetric underlying distributions. The charts' performances are compared in terms of the $\mathrm{TARL}_{1}$ and $\mathrm{TSDRL}_{1}$ criteria.

Future research can focus on extending the study on short run to other types of distribution-free control charts, including investigations on sign ranked charts. New research works can be conducted to investigate the EWMA, CUSUM and multivariate nonparametric charts for process monitoring in short run. Runs rules and adaptive sampling strategies can be adopted in short run control charts using the sign statistic. Finally, distribution-free control charts for monitoring process dispersion in short run can also be developed in a future research.

\section{References}

1. Parent EA Jr. Sequential Ranking Procedures, Technical Report No. 80, Department of Statistics, Stanford University, Stanford, California: 1965.

2. Reynolds Jr MR. A Sequential Nonparametric Test for Symmetry with Applications to Process Control (No. TR-148), Stanford University, California, Department of Operations Research:1972. 
3. Bakir ST. Nonparametric Procedures for Process Control, Ph.D. Dissertation, Department of Statistics, Virginia Polytechnic Institute and State University, Blacksburg, Virginia. 1977.

4. Bakir ST, Reynolds Jr MR. A nonparametric procedure for process control based on within-group ranking. Technometrics. 1779;21:175-183.

5. Park C. Some control procedures useful for one-sided asymmetrical distributions. $J$ Korean Stat Soc. 1985;14:76-86.

6. Amin RW, Searcy AJ. A nonparametric exponentially weighted moving average control scheme. Commun Stat-Simul C. 1991;20:1049-1072.

7. Amin RW, Reynolds Jr MR, Saad B. Nonparametric quality control charts based on the sign statistic. Commun Stat-Theor M. 1995;24:1597-1623.

8. Amin RW, Widmaier O. Sign control charts with variable sampling intervals. Commun Stat-Theor M. 1999;28:1961-1985.

9. Chakraborti S, Van der Laan P, Bakir ST. Nonparametric control charts: an overview and some results. J Qual Technol. 2001;33:304-309.

10. Bakir ST. A distribution-free Shewhart quality control chart based on signed-ranks. Qual Eng. 2004;16:613-623.

11. Bakir ST. Distribution-free quality control charts based on signed-rank-like statistics. Commun Stat-Theor M. 2006;35:743-757.

12. Chakraborti S, Eryilmaz S. A nonparametric Shewhart-type signed-rank control chart based on runs. Commun Stat-Simul C. 2007;36:335-356.

13. Chakraborti S, Graham MA. Nonparametric Control Charts, Encyclopedia of Quality and Reliability. New York: John Wiley \& Sons;2007.

14. Das N, Bhattacharya A. A new non-parametric control chart for controlling variability. Qual Technol Quant M. 2008;5:351-361. 
15. Li SY, Tang LC, Ng SH. Nonparametric CUSUM and EWMA control charts for detecting mean shifts. J Qual Technol. 2010;42:209-226.

16. Human SW, S Chakraborti, CF Smit. Nonparametric Shewhart-type sign control charts based on runs. Commun Stat-Theor M. 2010;39:2046-2062.

17. Graham MA, Chakraborti S, Human SW. A nonparametric EWMA sign chart for location based on individual measurements. Qual Eng. 2011;23:227-241.

18. Yang SF, Lin JS, Cheng SW. A new nonparametric EWMA sign control chart. Expert Syst Appl. 2011;38:6239-6243.

19. Aslam M, Azam M, Jun CH. A new exponentially weighted moving average sign chart using repetitive sampling. J Process Contr. 2014;24:1149-1153.

20. Lu SL. An extended nonparametric exponentially weighted moving average sign control chart. Qual Reliab Eng Int. 2015;31:3-13.

21. Asghari S, Sadeghpour Gildeh B, Ahmadi J, Mohtashami Borzadaran G. Sign control chart based on ranked set sampling. Qual Technol Quant M. 2018;15:568-588.

22. Chakraborti S, Graham MA. Nonparametric (distribution-free) control charts: An updated overview and some results. Qual Eng. 2019;31:523-544.

23. Ladany S. Optimal use of control charts for controlling current production. Manage Sci. 1973;19:763-772.

24. Ladany SP, Bedi DN. Selection of the optimal setup policy. Nav Res Logist. $1976 ; 23: 219-233$

25. Del Castillo E, Montgomery DC. Optimal design of control charts for monitoring short production runs. Econ Qual Contr. 1993;8:225-240.

26. Del Castillo E, Montgomery DC. A general model for the optimal economic design of $\bar{X}$ charts used to control short or long run processes. IIE Trans. 1996;28:193-201.

27. Calabrese JM. Bayesian process control for attributes. Manage Sci. 1995;41:637-645. 
28. Tagaras G. Dynamic control charts for finite production runs. Eur J Oper Res. 1996;91:38-55.

29. Tagaras G, Nikolaidis Y. Comparing the effectiveness of various Bayesian $\bar{X}$ control charts. Oper Res. 2002;50:878-888.

30. Nenes G, Tagaras G. The economically designed two-sided Bayesian $\bar{X}$ control chart. Eur J Oper Res. 2007;183:263-277.

31. Kooli I, Limam M. Bayesian $n p$ control charts with adaptive sample size for finite production runs. Qual Reliab Eng Int. 2009;25:439-448.

32. Nenes G, Tagaras G. Evaluation of CUSUM charts for finite-horizon processes. Commun Stat-Simul C. 2010;39:578-597.

33. Celano G, Castagliola P, Trovato E, Fichera S. Shewhart and EWMA $t$ control charts for short production runs. Qual Reliab Eng Int. 2011;27:313-326.

34. Celano, G, Castagliola P, Fichera S, Nenes G. Performance of $t$ control charts in short runs with unknown shift sizes. Comput Ind Eng. 2013;64:56-68.

35. Li Y, Pu X. On the Performance of Two-sided Control Charts for Short Production Runs. Qual Reliab Eng Int. 2012;28:215-232.

36. Castagliola P, Amdouni A, Taleb H, Celano G. One-sided Shewhart-type charts for monitoring the coefficient of variation in short production runs. Qual Technol Quant M. 2015;12:53-67.

37. Montgomery DC. Introduction to Statistical Quality Control. $6^{\text {th }}$ Edition. New York: John Wiley \& Sons:2009.

38. Celano G, Castagliola P, Chakraborti S, Nenes G. The performance of the Shewhart sign control chart for finite horizon processes. Int J Adv Manuf Tech. 2016a;84:14971512. 
39. Celano G, Castagliol P, Chakraborti S, Nenes G. On the implementation of the Shewhart sign control chart for low-volume production. Int $J$ Prod Res. 2016b;54:5886-5900.

40. Castagliola P, Celano G, Fichera S, Nenes G. The variable sample size $t$ control chart for monitoring short production runs. Int J Adv Manuf Tech. 2013;66:1353-1366.

41. Nenes G, Castagliola P, Celano G, Panagiotidou S. The variable sampling interval control chart for finite-horizon processes. IIE Trans. 2014;46:1050-1065.

42. Amdouni A, Castagliola P, Taleb H, Celano G. Monitoring the coefficient of variation using a variable sample size control chart in short production runs. Int J Adv Manuf Tech. 2015;81:1-14.

43. Park C, Choi K. Economic design of control charts with variable sample size schemes. In Annual Meeting of the American Statistical Association, Boston, MA.1992.

44. Park C, Reynolds MR. Economic design of a variable sample size-chart. Commun Stat-Simul C. 1994;23:467-483.

45. Park C, Reynolds MR. Economic design of a variable sampling rate $\bar{X}$ chart. J Qual Technol. 1999;31:427-443.

46. Croasdale R. Control charts for a double-sampling scheme based on average production run lengths. Int. J. Prod. Res. 1974;12:585-592.

47. Daudin JJ. Double sampling $\bar{X}$ charts. J Qual Technol. 1992;24:78-87.

48. Irianto D, Shinozaki N. An optimal double sampling $\bar{X}$ control chart. Int. J. Ind. Eng. -Theory. 1998;5:226-234.

49. Carot V, Jabaloyes JM, Carot T. Combined double sampling and variable sampling interval $\bar{X}$ chart. Int. J. Prod. Res. 2002;40:2175-2186. 
50. He D, Grigoryan A. Construction of double sampling $S$ control charts for agile manufacturing. Qual Reliab Eng Int. 2002;18:343-355.

\section{Data Availability Statement}

The data that support the findings of this study are openly available in reference number 37 . 
Table 1. The VSS SN short run chart's parameter combination $\left(n_{S}, n_{L}, c, k\right)$ and corresponding

\begin{tabular}{c|cccccccc}
\multicolumn{2}{c}{ TARL $_{0}, \mathrm{TSDRL}_{0}$ and $\mathrm{ASS}_{0}$ values for $I \in\{10,30,50\}$ and $n_{0} \in\{11,15,20\}$} \\
\hline$I$ & $n_{0}$ & $n_{S}$ & $n_{L}$ & $c$ & $k$ & $\mathrm{TARL}_{0}$ & $\mathrm{TSDRL}_{0}$ & $\mathrm{ASS}_{0}$ \\
\hline 10 & 11 & 9 & 13 & 7 & 2 & 10.16 & 1.97 & 10.91 \\
& 15 & 12 & 20 & 10 & 3 & 10.76 & 1.21 & 15.07 \\
& 20 & 15 & 31 & 13 & 4 & 10.83 & 1.04 & 20.06 \\
\hline 30 & 11 & 10 & 19 & 8 & 7 & 30.21 & 5.33 & 10.18 \\
& 15 & 13 & 21 & 11 & 4 & 30.01 & 4.37 & 15.30 \\
& 20 & 15 & 23 & 13 & 2 & 30.27 & 5.48 & 20.02 \\
\hline 50 & 11 & - & - & & - & - & - & - \\
& 15 & 14 & 26 & 12 & 7 & 50.14 & 6.40 & 14.75 \\
& 20 & 16 & 24 & 14 & 3 & 50.05 & 6.00 & 20.00 \\
\hline
\end{tabular}


Table 2. TARL 1 (first line of $\delta$ ) and $\mathrm{TSDRL}_{1}$ (second line of $\delta$ ) values for the FSS and VSS SN short run charts when $I=10$ and $n_{0}=11$ with the chart's parameters $n_{S}=9, n_{L}=13, c=7$ and $k=2$, for different underlying distributions

\begin{tabular}{|c|c|c|c|c|c|c|c|c|c|c|c|c|}
\hline $\begin{array}{c}\text { Shift } \\
\text { size, } \\
\delta\end{array}$ & $\begin{array}{c}N(0,1) \\
\text { FSS }\end{array}$ & $\begin{array}{c}N(0,1) \\
\text { VSS }\end{array}$ & $\begin{array}{l}t(4) \\
\text { FSS }\end{array}$ & $\begin{array}{l}t(4) \\
\text { VSS }\end{array}$ & $\begin{array}{l}t(8) \\
\text { FSS }\end{array}$ & $\begin{array}{l}t(8) \\
\text { VSS }\end{array}$ & $\begin{array}{c}\operatorname{gam}(0.5 \\
1) \\
\text { FSS }\end{array}$ & $\begin{array}{c}\operatorname{gam}(0.5 \\
1) \\
\text { VSS }\end{array}$ & $\begin{array}{c}\operatorname{gam}(1, \\
1) \\
\text { FSS }\end{array}$ & $\begin{array}{c}\operatorname{gam}(1, \\
1) \\
\text { VSS }\end{array}$ & $\begin{array}{c}\text { laplace } \\
\text { FSS }\end{array}$ & $\begin{array}{c}\text { laplace } \\
\text { VSS }\end{array}$ \\
\hline \multirow[t]{2}{*}{0.2} & 9.89 & 8.96 & 9.83 & 8.58 & 9.86 & 8.59 & 7.65 & 3.38 & 8.36 & 4.12 & 9.79 & 8.15 \\
\hline & 0.81 & 2.25 & 1.01 & 2.53 & 0.94 & 2.52 & 3.15 & 1.97 & 2.83 & 2.48 & 1.13 & 2.77 \\
\hline \multirow[t]{2}{*}{0.4} & 9.60 & 7.13 & 9.18 & 5.65 & 9.45 & 5.82 & 2.31 & 1.54 & 2.93 & 1.68 & 8.98 & 5.12 \\
\hline & 1.54 & 3.09 & 2.14 & 3.07 & 1.78 & 3.04 & 1.65 & 0.57 & 2.20 & 0.63 & 2.36 & 2.88 \\
\hline \multirow[t]{2}{*}{0.6} & 8.82 & 4.72 & 7.58 & 3.28 & 8.35 & 3.48 & 1.19 & 1.13 & 1.31 & 1.20 & 7.43 & 3.10 \\
\hline & 2.51 & 2.77 & 3.20 & 1.92 & 2.85 & 2.00 & 0.48 & 0.34 & 0.64 & 0.40 & 3.21 & 1.79 \\
\hline \multirow{2}{*}{0.8} & 7.23 & 3.07 & 5.43 & 2.26 & 6.66 & 2.38 & 1.02 & 1.01 & 1.05 & 1.04 & 5.44 & 2.26 \\
\hline & 3.32 & 1.74 & 3.34 & 1.11 & 3.38 & 1.09 & 0.14 & 0.12 & 0.22 & 0.18 & 3.34 & 1.08 \\
\hline \multirow[t]{2}{*}{1} & 5.44 & 2.23 & 3.66 & 1.83 & 4.71 & 1.93 & 1.00 & 1.00 & 1.00 & 1.00 & 3.89 & 1.88 \\
\hline & 3.35 & 1.00 & 2.71 & 0.74 & 3.12 & 0.72 & 0.03 & 0.03 & 0.07 & 0.06 & 2.85 & 0.77 \\
\hline \multirow[t]{2}{*}{1.25} & 3.31 & 1.76 & 2.37 & 1.55 & 2.91 & 1.63 & 1.00 & 1.00 & 1.00 & 1.00 & 2.63 & 1.61 \\
\hline & 2.48 & 0.68 & 1.74 & 0.58 & 2.22 & 0.58 & 0.00 & 0.00 & 0.00 & 0.00 & 2.00 & 0.61 \\
\hline \multirow[t]{2}{*}{1.5} & 2.15 & 1.50 & 1.76 & 1.38 & 1.97 & 1.45 & 1.00 & 1.00 & 1.00 & 1.00 & 1.96 & 1.43 \\
\hline & 1.55 & 0.56 & 1.15 & 0.51 & 1.37 & 0.52 & 0.00 & 0.00 & 0.00 & 0.00 & 1.38 & 0.53 \\
\hline \multirow[t]{2}{*}{1.75} & 1.58 & 1.31 & 1.47 & 1.28 & 1.54 & 1.30 & 1.00 & 1.00 & 1.00 & 1.00 & 1.59 & 1.31 \\
\hline & 0.97 & 0.47 & 0.83 & 0.46 & 0.92 & 0.47 & 0.00 & 0.00 & 0.00 & 0.00 & 0.99 & 0.47 \\
\hline \multirow[t]{2}{*}{2} & 1.30 & 1.19 & 1.31 & 1.20 & 1.32 & 1.20 & 1.00 & 1.00 & 1.00 & 1.00 & 1.38 & 1.23 \\
\hline & 0.61 & 0.39 & 0.63 & 0.40 & 0.65 & 0.41 & 0.00 & 0.00 & 0.00 & 0.00 & 0.74 & 0.42 \\
\hline \multirow[t]{2}{*}{2.5} & 1.07 & 1.06 & 1.14 & 1.11 & 1.12 & 1.09 & 1.00 & 1.00 & 1.00 & 1.00 & 1.17 & 1.12 \\
\hline & 0.28 & 0.23 & 0.39 & 0.31 & 0.37 & 0.29 & 0.00 & 0.00 & 0.00 & 0.00 & 0.45 & 0.32 \\
\hline \multirow[t]{2}{*}{3} & 1.02 & 1.01 & 1.08 & 1.06 & 1.05 & 1.04 & 1.00 & 1.00 & 1.00 & 1.00 & 1.09 & 1.07 \\
\hline & 0.12 & 0.11 & 0.29 & 0.24 & 0.22 & 0.20 & 0.00 & 0.00 & 0.00 & 0.00 & 0.32 & 0.25 \\
\hline
\end{tabular}


Table 3. TARL 1 (first line of $\delta$ ) and TSDRL 1 (second line of $\delta$ ) values for the FSS and VSS SN short run charts when $I=30$ and $n_{0}=15$ with the chart's parameters $n_{S}=13, n_{L}=21, c=11$ and $k=4$, for different underlying distributions

\begin{tabular}{|c|c|c|c|c|c|c|c|c|c|c|c|c|}
\hline $\begin{array}{c}\text { Shift } \\
\text { size, } \\
\delta\end{array}$ & $\begin{array}{c}N(0,1) \\
\text { FSS }\end{array}$ & $\begin{array}{c}N(0,1) \\
\text { VSS }\end{array}$ & $\begin{array}{l}t(4) \\
\text { FSS }\end{array}$ & $\begin{array}{c}t(4) \\
\text { VSS }\end{array}$ & $\begin{array}{l}t(8) \\
\text { FSS }\end{array}$ & $\begin{array}{c}t(8) \\
\text { VSS }\end{array}$ & $\begin{array}{c}\operatorname{gam}(0.5 \\
1) \\
\text { FSS }\end{array}$ & $\begin{array}{c}\operatorname{gam}(0.5 \\
1) \\
\text { VSS }\end{array}$ & $\begin{array}{c}\operatorname{gam}(1, \\
1) \\
\text { FSS } \\
\end{array}$ & $\begin{array}{c}\operatorname{gam}(1, \\
1) \\
\text { VSS } \\
\end{array}$ & $\begin{array}{c}\text { laplace } \\
\text { FSS }\end{array}$ & $\begin{array}{c}\text { laplace } \\
\text { VSS }\end{array}$ \\
\hline \multirow[t]{2}{*}{0.20} & 29.87 & 26.03 & 29.79 & 23.23 & 29.86 & 23.70 & 22.28 & 3.28 & 25.20 & 4.28 & 29.65 & 20.22 \\
\hline & 1.49 & 7.87 & 2.03 & 9.45 & 1.67 & 9.21 & 9.90 & 1.74 & 8.62 & 2.67 & 2.61 & 10.09 \\
\hline \multirow[t]{2}{*}{0.40} & 29.27 & 14.09 & 28.04 & 7.58 & 28.86 & 8.05 & 3.10 & 1.65 & 4.42 & 1.75 & 27.31 & 5.97 \\
\hline & 3.68 & 9.54 & 5.89 & 5.79 & 4.64 & 6.10 & 2.53 & 0.50 & 3.87 & 0.51 & 6.85 & 4.33 \\
\hline \multirow[t]{2}{*}{0.60} & 26.71 & 5.31 & 21.99 & 3.20 & 25.19 & 3.35 & 1.27 & 1.19 & 1.46 & 1.28 & 20.65 & 3.00 \\
\hline & 7.40 & 3.78 & 10.03 & 1.65 & 8.61 & 1.72 & 0.58 & 0.39 & 0.83 & 0.45 & 10.39 & 1.45 \\
\hline \multirow[t]{2}{*}{0.80} & 20.67 & 2.95 & 12.43 & 2.23 & 17.42 & 2.34 & 1.03 & 1.02 & 1.07 & 1.05 & 12.39 & 2.22 \\
\hline & 10.32 & 1.43 & 9.49 & 0.81 & 10.66 & 0.81 & 0.17 & 0.15 & 0.26 & 0.23 & 9.44 & 0.79 \\
\hline \multirow[t]{2}{*}{1.00} & 12.20 & 2.20 & 6.20 & 1.88 & 9.52 & 1.96 & 1.00 & 1.00 & 1.01 & 1.01 & 6.87 & 1.91 \\
\hline & 9.30 & 0.74 & 5.60 & 0.54 & 8.01 & 0.52 & 0.04 & 0.03 & 0.08 & 0.07 & 6.16 & 0.56 \\
\hline \multirow[t]{2}{*}{1.25} & 5.36 & 1.82 & 3.31 & 1.66 & 4.35 & 1.74 & 1.00 & 1.00 & 1.00 & 1.00 & 3.81 & 1.71 \\
\hline & 4.79 & 0.52 & 2.78 & 0.50 & 3.84 & 0.48 & 0.00 & 0.00 & 0.00 & 0.00 & 3.22 & 0.50 \\
\hline \multirow[t]{2}{*}{1.50} & 2.80 & 1.60 & 2.19 & 1.50 & 2.52 & 1.55 & 1.00 & 1.00 & 1.00 & 1.00 & 2.52 & 1.55 \\
\hline & 2.26 & 0.50 & 1.64 & 0.50 & 1.98 & 0.50 & 0.00 & 0.00 & 0.00 & 0.00 & 1.98 & 0.50 \\
\hline \multirow[t]{2}{*}{1.75} & 1.85 & 1.41 & 1.70 & 1.36 & 1.80 & 1.40 & 1.00 & 1.00 & 1.00 & 1.00 & 1.89 & 1.43 \\
\hline & 1.28 & 0.49 & 1.11 & 0.48 & 1.22 & 0.49 & 0.00 & 0.00 & 0.00 & 0.00 & 1.31 & 0.50 \\
\hline \multirow[t]{2}{*}{2.00} & 1.43 & 1.27 & 1.43 & 1.27 & 1.45 & 1.27 & 1.00 & 1.00 & 1.00 & 1.00 & 1.56 & 1.32 \\
\hline & 0.78 & 0.44 & 0.79 & 0.44 & 0.82 & 0.44 & 0.00 & 0.00 & 0.00 & 0.00 & 0.93 & 0.47 \\
\hline \multirow[t]{2}{*}{2.50} & 1.10 & 1.10 & 1.20 & 1.15 & 1.16 & 1.12 & 1.00 & 1.00 & 1.00 & 1.00 & 1.25 & 1.18 \\
\hline & 0.34 & 0.27 & 0.49 & 0.35 & 0.44 & 0.33 & 0.00 & 0.00 & 0.00 & 0.00 & 0.55 & 0.38 \\
\hline \multirow[t]{2}{*}{3.00} & 1.02 & 1.01 & 1.10 & 1.08 & 1.06 & 1.05 & 1.00 & 1.00 & 1.00 & 1.00 & 1.13 & 1.10 \\
\hline & 0.15 & 0.14 & 0.33 & 0.28 & 0.26 & 0.22 & 0.00 & 0.00 & 0.00 & 0.00 & 0.38 & 0.29 \\
\hline
\end{tabular}


Table 4. TARL 1 (first line of $\delta$ ) and TSDRL 1 (second line of $\delta$ ) values for the FSS and VSS SN short run charts when $I=50$ and $n_{0}=20$ with the chart's parameters $n_{S}=16, n_{L}=24, c=14$ and $k=3$, for different underlying distributions

\begin{tabular}{|c|c|c|c|c|c|c|c|c|c|c|c|c|}
\hline $\begin{array}{c}\text { Shift } \\
\text { size, } \\
\delta\end{array}$ & $\begin{array}{c}N(0,1) \\
\text { FSS }\end{array}$ & $\begin{array}{c}N(0,1) \\
\text { VSS }\end{array}$ & $\begin{array}{l}t(4) \\
\text { FSS }\end{array}$ & $\begin{array}{c}t(4) \\
\text { VSS }\end{array}$ & $\begin{array}{l}t(8) \\
\text { FSS }\end{array}$ & $\begin{array}{c}t(8) \\
\text { VSS }\end{array}$ & $\begin{array}{c}\operatorname{gam}(0.5 \\
1) \\
\text { FSS }\end{array}$ & $\begin{array}{c}\operatorname{gam}(0.5 \\
1) \\
\text { VSS }\end{array}$ & $\begin{array}{c}\operatorname{gam}(1, \\
1) \\
\text { FSS }\end{array}$ & $\begin{array}{c}\operatorname{gam}(1, \\
1) \\
\text { VSS }\end{array}$ & $\begin{array}{c}\text { laplace } \\
\text { FSS }\end{array}$ & $\begin{array}{c}\text { laplace } \\
\text { VSS }\end{array}$ \\
\hline \multirow[t]{2}{*}{0.20} & 49.99 & 44.55 & 49.96 & 39.79 & 49.98 & 39.66 & 43.10 & 3.96 & 46.85 & 5.48 & 49.87 & 34.26 \\
\hline & 0.33 & 12.30 & 1.18 & 15.45 & 0.95 & 15.54 & 13.74 & 2.44 & 9.74 & 3.99 & 2.13 & 17.25 \\
\hline \multirow[t]{2}{*}{0.40} & 49.82 & 23.13 & 48.96 & 11.09 & 49.57 & 11.27 & 4.52 & 1.72 & 7.03 & 1.86 & 48.34 & 8.31 \\
\hline & 2.35 & 16.33 & 5.74 & 9.06 & 3.70 & 9.30 & 3.97 & 0.49 & 6.75 & 0.51 & 7.28 & 6.70 \\
\hline \multirow[t]{2}{*}{0.60} & 48.01 & 7.13 & 42.75 & 3.86 & 46.62 & 3.89 & 1.37 & 1.22 & 1.83 & 1.34 & 41.34 & 3.51 \\
\hline & 7.90 & 5.48 & 13.92 & 2.35 & 10.00 & 2.26 & 0.69 & 0.42 & 1.21 & 0.47 & 14.80 & 1.98 \\
\hline \multirow[t]{2}{*}{0.80} & 40.86 & 3.47 & 26.11 & 2.44 & 36.11 & 2.49 & 1.04 & 1.03 & 1.09 & 1.06 & 26.06 & 2.41 \\
\hline & 15.22 & 1.98 & 17.34 & 0.94 & 17.00 & 0.93 & 0.19 & 0.16 & 0.31 & 0.25 & 17.52 & 0.91 \\
\hline \multirow[t]{2}{*}{1.00} & 25.23 & 2.40 & 11.39 & 2.00 & 19.25 & 2.07 & 1.00 & 1.00 & 1.01 & 1.01 & 12.73 & 2.04 \\
\hline & 17.46 & 0.90 & 10.32 & 0.59 & 15.50 & 0.53 & 0.04 & 0.04 & 0.09 & 0.08 & 11.50 & 0.61 \\
\hline \multirow{2}{*}{1.25} & 9.38 & 1.92 & 4.82 & 1.75 & 7.17 & 1.82 & 1.00 & 1.00 & 1.00 & 1.00 & 5.91 & 1.80 \\
\hline & 8.62 & 0.52 & 4.23 & 0.49 & 6.68 & 0.46 & 0.00 & 0.00 & 0.00 & 0.00 & 5.45 & 0.49 \\
\hline \multirow[t]{2}{*}{1.50} & 3.97 & 1.69 & 2.81 & 1.57 & 3.47 & 1.64 & 1.00 & 1.00 & 1.00 & 1.00 & 3.41 & 1.63 \\
\hline & 3.40 & 0.49 & 2.26 & 0.50 & 2.86 & 0.49 & 0.00 & 0.00 & 0.00 & 0.00 & 2.95 & 0.50 \\
\hline \multirow[t]{2}{*}{1.75} & 2.25 & 1.48 & 2.00 & 1.44 & 2.20 & 1.47 & 1.00 & 1.00 & 1.00 & 1.00 & 2.33 & 1.50 \\
\hline & 1.70 & 0.50 & 1.40 & 0.50 & 1.61 & 0.50 & 0.00 & 0.00 & 0.00 & 0.00 & 1.77 & 0.50 \\
\hline \multirow[t]{2}{*}{2.00} & 1.60 & 1.32 & 1.61 & 1.32 & 1.66 & 1.33 & 1.00 & 1.00 & 1.00 & 1.00 & 1.81 & 1.38 \\
\hline & 0.98 & 0.47 & 0.99 & 0.47 & 1.05 & 0.47 & 0.00 & 0.00 & 0.00 & 0.00 & 1.19 & 0.49 \\
\hline \multirow[t]{2}{*}{2.50} & 1.13 & 1.10 & 1.27 & 1.18 & 1.23 & 1.15 & 1.00 & 1.00 & 1.00 & 1.00 & 1.34 & 1.22 \\
\hline & 0.40 & 0.30 & 0.59 & 0.38 & 0.53 & 0.35 & 0.00 & 0.00 & 0.00 & 0.00 & 0.67 & 0.41 \\
\hline \multirow[t]{2}{*}{3.00} & 1.03 & 1.02 & 1.14 & 1.10 & 1.08 & 1.06 & 1.00 & 1.00 & 1.00 & 1.00 & 1.16 & 1.12 \\
\hline & 0.17 & 0.15 & 0.40 & 0.29 & 0.30 & 0.24 & 0.00 & 0.00 & 0.00 & 0.00 & 0.42 & 0.32 \\
\hline
\end{tabular}


Table 5. Fill volume data of soft drink beverage bottles

\begin{tabular}{|c|c|c|c|c|c|c|c|c|c|c|c|c|c|c|c|c|c|c|c|c|c|c|c|c|c|c|}
\hline \multirow{2}{*}{$\begin{array}{l}\text { Sample } \\
\text { number }\end{array}$} & \multicolumn{14}{|c|}{ Data for the VSS SN short run chart } & \multicolumn{12}{|c|}{ Data for the FSS SN short run chart } \\
\hline & $x_{i, 1}$ & $x_{i, 2}$ & $x_{i, 3}$ & $x_{i, 4}$ & $x_{i, 5}$ & $x_{i, 6}$ & $x_{i, 7}$ & $x_{i, 8}$ & $x_{i, 9}$ & $x_{i, 10}$ & $x_{i, 11}$ & $x_{i, 12}$ & $x_{i, 13}$ & $S N_{i}$ & $x_{i, 1}$ & $x_{i, 2}$ & $x_{i, 3}$ & $x_{i, 4}$ & $x_{i, 5}$ & $x_{i, 6}$ & $x_{i, 7}$ & $x_{i, 8}$ & $x_{i, 9}$ & $x_{i, 10}$ & $x_{i, 11}$ & $S N_{i}$ \\
\hline 1 & 2.5 & 0.5 & 2.0 & -1.0 & 1.0 & -1.0 & 0.5 & 1.5 & 0.5 & & & & & 5 & 2.5 & 0.5 & 2.0 & -1.0 & 1.0 & -1.0 & 0.5 & 1.5 & 0.5 & -1.5 & 0.5 & 5 \\
\hline 2 & -1.5 & 0.5 & 1.0 & 1.5 & 1.0 & -1.0 & 1.0 & 1.5 & -1.0 & 1.5 & 1.0 & 1.0 & -1.0 & 5 & 1.0 & 1.5 & 1.0 & -1.0 & 1.0 & 1.5 & -1.0 & 1.5 & 1.0 & 1.0 & -1.0 & 5 \\
\hline 3 & -1.5 & -1.0 & -1.0 & 1.0 & -1.0 & 0.5 & -2.0 & -1.0 & 1.5 & -1.5 & -2.0 & -1.5 & -0.5 & -7 & -1.5 & -1.0 & -1.0 & 1.0 & -1.0 & 0.5 & -2.0 & -1.0 & 1.5 & -1.5 & -2.0 & -5 \\
\hline 4 & 0.5 & 1.0 & -0.5 & -0.5 & 1.0 & -0.5 & 0.5 & -1.0 & 1.0 & -2.0 & 1.0 & 1.0 & -1.0 & 1 & -1.5 & -0.5 & 0.5 & 1.0 & -0.5 & -0.5 & 1.0 & -0.5 & 0.5 & -1.0 & 1.0 & -1 \\
\hline 5 & -1.0 & -1.0 & 1.5 & 1.0 & -1.5 & -0.5 & 1.5 & -1.0 & 0.5 & & & & & -1 & -2.0 & 1.0 & 1.0 & -1.0 & -1.0 & -1.0 & 1.5 & 1.0 & -1.5 & -0.5 & 1.5 & -1 \\
\hline 6 & -0.5 & -2.0 & -1.5 & 1.5 & 1.5 & 0.5 & 1.0 & 1.0 & -0.5 & & & & & 1 & -1.0 & 0.5 & -0.5 & -2.0 & -1.5 & 1.5 & 1.5 & 0.5 & 1.0 & 1.0 & -0.5 & 1 \\
\hline 7 & 3.5 & -1.0 & -1.5 & -1.5 & -1.0 & -1.0 & 1.0 & 0.5 & 1.5 & & & & & -1 & 3.5 & -1.0 & -1.5 & -1.5 & -1.0 & -1.0 & 1.0 & 0.5 & 1.5 & 2.0 & -1.5 & -1 \\
\hline 8 & 2.0 & -1.5 & 0.5 & -0.5 & 2.0 & -1.0 & -2.0 & -0.5 & -0.5 & & & & & -3 & 0.5 & -0.5 & 2.0 & -1.0 & -2.0 & -0.5 & -0.5 & 2.0 & -1.5 & -0.5 & -1.0 & -5 \\
\hline 9 & 2.0 & -1.5 & -0.5 & -1.0 & -1.0 & -0.5 & -0.5 & -1.0 & 0.5 & -0.5 & -1.0 & -1.0 & -1.0 & -9 & -1.0 & -0.5 & -0.5 & -1.0 & 0.5 & -0.5 & -1.0 & -1.0 & -1.0 & 0.5 & 1.0 & -5 \\
\hline 10 & 0.5 & 1.0 & -1.0 & -0.5 & -2.0 & -1.0 & -1.5 & 1.5 & 1.5 & & & & & -1 & -1.0 & -0.5 & -2.0 & -1.0 & -1.5 & 1.5 & 1.5 & 1.0 & 1.5 & 1.5 & 1.0 & 1 \\
\hline
\end{tabular}




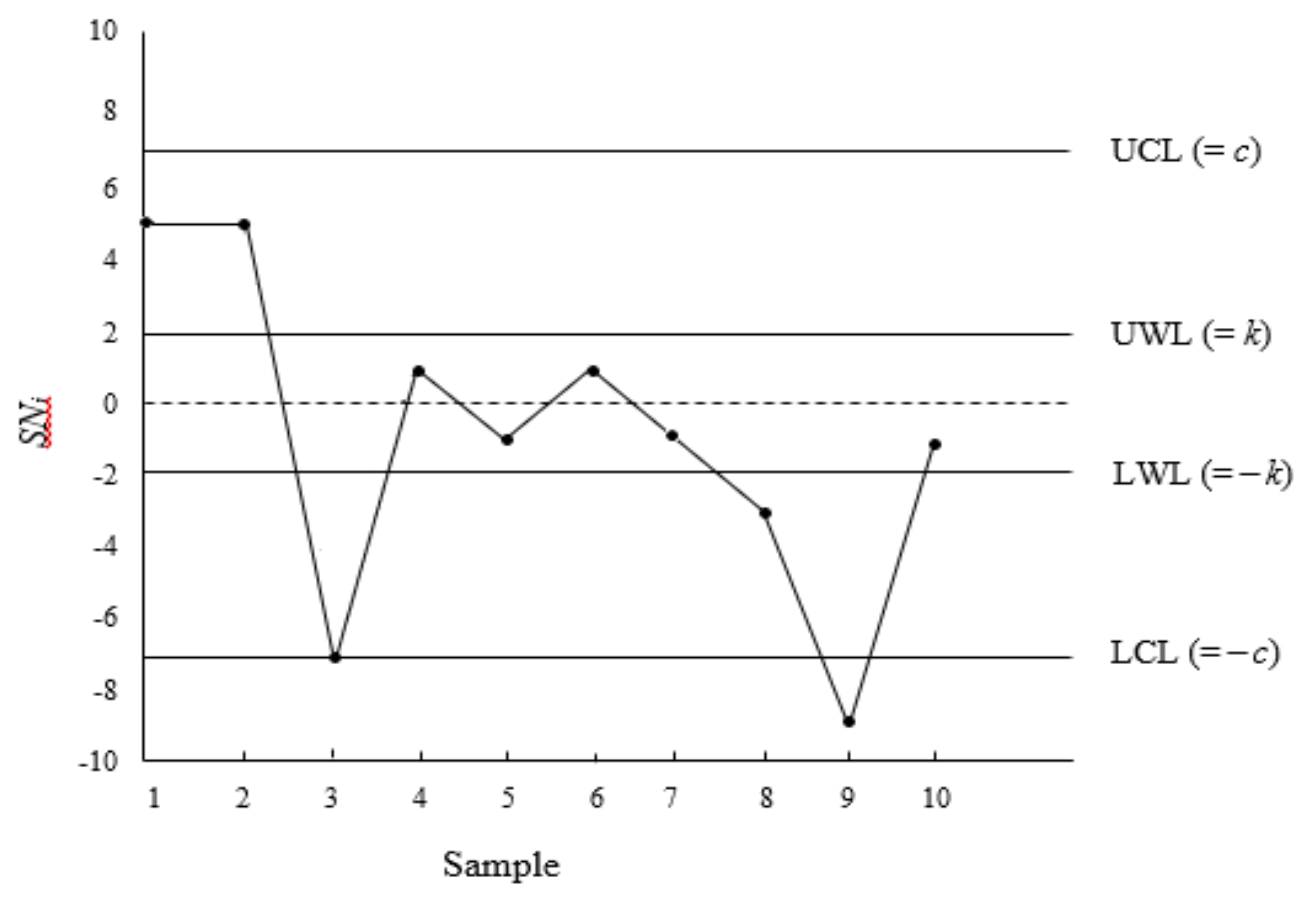

Figure 1. VSS SN short run chart for the fill volume of soft drink beverage bottles

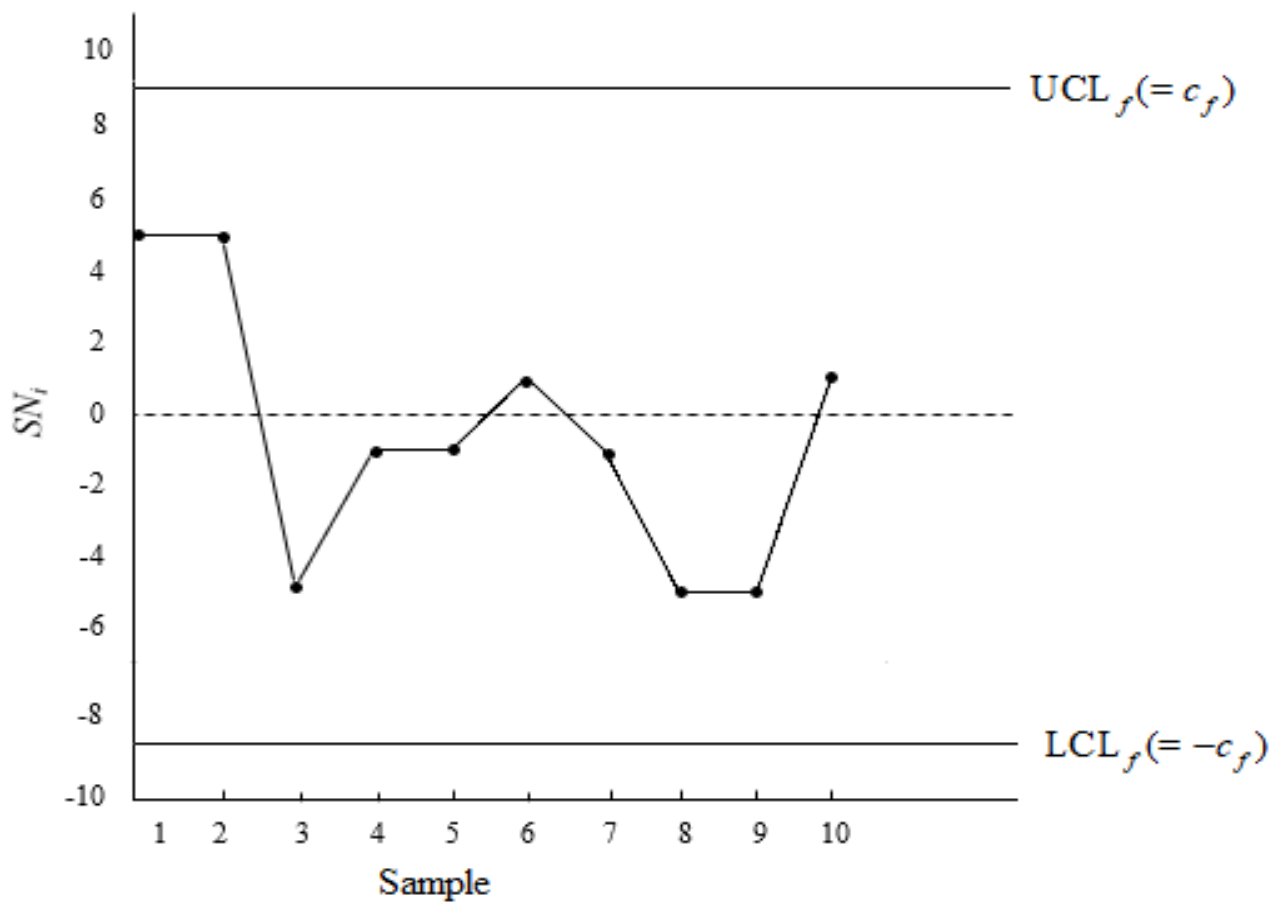

Figure 2. FSS SN short run chart for the fill volume of soft drink beverage bottles 